\title{
(2) OPEN ACCESS \\ Two-year observation of posterior corneal elevations after small incision lenticule extraction (SMILE) for myopia higher than -10 dioptres
}

\author{
Xueyi Zhou, ${ }^{1,2}$ Jianmin Shang, ${ }^{1,2}$ Bing Qin, ${ }^{1,2}$ Yu Zhao, ${ }^{1,2}$ Xingtao Zhou (1) 1,2
}

${ }^{1}$ Ophthalmology, Eye and ENT Hospital of Fudan University, NHC Key Laboratory of Myopia, Shanghai, China

'Laboratory of Myopia, Chinese Academy of Medical Sciences, Shanghai, China

Correspondence to Dr Xingtao Zhou, Ophthalmology, Eye and ENT Hospital of Fudan University, Shanghai 200433, China; doctzhouxingtao@163.com

$\mathrm{XZ}$ and JS contributed equally.

Received 4 November 2018 Revised 5 February 2019 Accepted 29 March 2019 Published Online First 29 April 2019

\section{Check for updates}

(C) Author(s) (or their employer(s)) 2020. Re-use permitted under CC BY-NC. No commercial re-use. See rights and permissions. Published by BMJ.

To cite: Zhou $X$, Shang J Qin B, et al. Br J Ophthalmol 2020;104:142-148.

\section{ABSTRACT}

Aim To investigate the change in posterior corneal elevations (PCEs) of eyes with extremely high myopia 2 years after small incision lenticule extraction (SMILE). Methods We evaluated 39 eyes of 39 patients with spherical equivalent higher than -10.00 dioptres (D). Using a Scheimpflug camera (Pentacam), we measured change in PCEs at 1 day, 3 months, 6 months and 2 years after SMILE. Another 34 eyes of 34 patients who underwent femtosecond laser-assisted in situ keratomileusis (FS-LASIK) were examined before, at 1 day and long-term after surgery as the control group. For each eye, elevations at central, thinnest, maximal points and 24 other predetermined points were measured. Results No significant forward displacements of PCEs were observed in both surgeries. The maximal but not significant forward displacement occurred around 3-6 months following SMILE, and all returned to original levels 6 months postoperatively except superior area. The peripheral area tended to displace backward, while the central area tended forwardly. In both procedures, elevations along horizontal meridians, inferior and temporal hemispheres were significantly higher than those along vertical meridians, superior and nasal hemispheres, respectively $(p<0.05)$. Elevation on the $4 \mathrm{~mm}, 6 \mathrm{~mm}$ diameters at 1 day and on the $6 \mathrm{~mm}$ diameter and temporal hemisphere at long-term followup postoperatively were significantly higher in FS-LASIK than SMILE $(p<0.05)$. Change in elevations on the $6 \mathrm{~mm}$ diameter circle correlated with residual bed thickness ( $p=0.047)$.

Conclusions SMILE is a safe way to correct for myopia higher than $-10 D$, with PCEs remaining stable 2 years after surgery.

Small incision lenticule extraction (SMILE), first introduced by Sekundo and Shah in 2011, is a flap-free and minimally invasive variant of femtosecond lenticule extraction. ${ }^{1}$ Its safety, efficacy, predictability and stability have been widely confirmed, ${ }^{2} 3$ leading to increased researches on its effects on corneal morphology and biomechanical properties.

Due to its flap-free procedure, more of the anterior stroma remains intact after SMILE. This theoretically contributes to better preservation of corneal biomechanics. ${ }^{4}$ Keratoconus is one of the most serious postoperative complications. ${ }^{5}$ Posterior corneal elevation is a highly specific and effective indicator for early stage corneal ectasia. ${ }^{67}$ Many studies were done on the forward displacement of the posterior surface after undergoing laser-assisted in situ keratomileusis (LASIK). ${ }^{8}$ However, studies on elevations after SMILE have been insufficient. Previous studies show a higher risk of postoperative ectasia in patients with high myopia. ${ }^{8}$ Considering the thinner cornea and weaker corneal strength caused by the increased tissue removal in patients with high myopia, the stability of their posterior corneal surface needs better assessment.

\section{METHODS}

\section{Patients}

This prospective non-randomised cohort study evaluates the long-term stability of posterior corneal elevation in eyes with extremely high myopia after SMILE and femtosecond laser-assisted in situ keratomileusis (FS-LASIK). Patients were recruited in a continuous cohort between June 2015 and February 2016 at Eye and ENT Hospital of Fudan University (Shanghai, China).

Patient inclusion criteria: spherical equivalent $(\mathrm{SE}) \geq-10$ dioptres $(\mathrm{D})$, astigmatism $<5 \mathrm{D}$, corrected distance visual acuity (CDVA) $\geq 20 / 32$, sufficient corneal thickness (estimated postoperative corneal thickness $>400 \mu \mathrm{m}$ and residual bed thickness [RBT] $>250 \mu \mathrm{m}$ ), stable refractive error in the preceding 2 years and no use of contact lenses within preceding 2 weeks.

Patient exclusion criteria: systemic or other ocular diseases, history of ocular surgeries or trauma, suspicion of keratectasia or dry eye.

All individuals were healthy, routinely screened and met the criteria for two surgeries. Thirty-nine participants (12 male and 27 female) who underwent SMILE were examined before, at 1 day, 1 month, 3 months, 6 months and 2 years after surgery. Another 34 participants (12 males and 22 females) who underwent FS-LASIK were examined before, at 1 day and at least 1 year $(18.2 \pm 5.9$ months, range from 12 to 33 months) after surgery as the control group. One random eye from each participant was analysed. Detailed patient information is shown in table 1.

\section{Surgical procedures}

SMILE was performed using VisuMax femtosecond laser system (Carl Zeiss Meditec, Jena, Germany) with a repetition rate of $500 \mathrm{kHz}$ and a pulse energy of $130 \mathrm{~nJ}$. Lenticule diameter was set to $6 \mathrm{~mm}$. The intended corneal cap thickness was set to 100-120 $\mu \mathrm{m}$ with a diameter of $7.5 \mathrm{~mm}$. The procedure is described previously. ${ }^{10}$ 


\begin{tabular}{|c|c|c|c|}
\hline Parameters & SMILE $(n=39)$ & FS-LASIK $(n=34)$ & $P$ value \\
\hline Age (years) & $31.18 \pm 9.36(21 \sim 56)$ & $35.95 \pm 12.48(23 \sim 63)$ & 0.073 \\
\hline Sphere (D) & $\begin{array}{l}-10.13 \pm 0.96 \\
(-7.75 \sim-13.00)\end{array}$ & $\begin{array}{l}-10.32 \pm 1.14 \\
(-8.25 \sim-13.25)\end{array}$ & 0.445 \\
\hline Cylinder (D) & $-1.30 \pm 1.00(0 \sim-4.50)$ & $-1.56 \pm 0.86(-0.25 \sim-3.50)$ & 0.249 \\
\hline SE (D) & $\begin{array}{l}-10.79 \pm 0.81 \\
(-10.00 \sim-13.00)\end{array}$ & $\begin{array}{l}-11.06 \pm 0.99 \\
(-10.00 \sim-14.50)\end{array}$ & 0.797 \\
\hline UDVA & $0.03 \pm 0.03(0.01 \sim 0.10)$ & $0.02 \pm 0.03(0.01 \sim 0.10)$ & 0.468 \\
\hline CDVA & $0.99 \pm 0.13(0.60 \sim 1.20)$ & $0.96 \pm 0.15(0.06 \sim 1.20)$ & 0.301 \\
\hline $\mathrm{TCT}(\mu \mathrm{m})$ & $545.3 \pm 23.4(503 \sim 597)$ & $553.3 \pm 36.1(498 \sim 620)$ & 0.244 \\
\hline IOP $(\mathrm{mm} \mathrm{Hg})$ & $16.52 \pm 2.36(12.2 \sim 22.0)$ & $15.68 \pm 3.30(9.0 \sim 21.1)$ & 0.220 \\
\hline Optical zone (mm) & $6.14 \pm 0.21(5.75 \sim 6.50)$ & $5.97 \pm 0.20(5.75 \sim 6.50)$ & 0.001 \\
\hline Ablation depth ( $\mu \mathrm{m})$ & $\begin{array}{l}151.54 \pm 6.59 \\
(132.00 \sim 163.00)\end{array}$ & $147.79 \pm 9.40(124 \sim 160)$ & 0.057 \\
\hline $\mathrm{RBT}(\mu \mathrm{m})$ & $\begin{array}{l}278.90 \pm 17.29 \\
(253.00 \sim 319.00)\end{array}$ & $316.03 \pm 33.15(267 \sim 376)$ & 0.000 \\
\hline
\end{tabular}

CDVA, corrected distance visual acuity; D, dioptres; FS-LASIK, femtosecond laser-assisted in situ keratomileusis; IOP, intraocular pressure; RBT, residual bed thickness; $S E$, spherical equivalent; SMILE, small incision lenticule extraction; TCT, thinnest corneal thickness; UDVA, uncorrected distance visual acuity.

In the FS-LASIK procedures, the same femtosecond laser system was used for flap creation with a pulse energy of 185 nJ, followed by a MEL 80 excimer laser (Carl Zeiss Meditec, Oberkochen, Germany) for stromal ablation with a repetition rate of $250 \mathrm{~Hz}$ and a pulse energy of $1.00 \pm 0.15 \mathrm{~mJ}$. The intended flap thickness was set to $100 \mu \mathrm{m}$ with a diameter of $8 \mathrm{~mm}$. The hinges were located at a superior 12 o'clock with a length of $4.0 \mathrm{~mm}$.

All surgeries were performed by an experienced surgeon (XTZ). Prior to surgery, 0.5\% topical levofloxacin (Cravit; Santen, Osaka, Japan) was applied four to six times daily for 3 days. A bandage soft contact lens was applied for 1 day after FS-LASIK. After both procedures, 0.5\% topical levofloxacin, $0.1 \%$ fluorometholone solution and non-preserved artificial tears (carboxymethylcellulose sodium eye drops; Allergan, Irvine, California, USA) were applied.

\section{Clinical examinations}

Posterior corneal elevation measurements were obtained using the Pentacam HR (Oculus GmbH, Wetzlar, Germany). ${ }^{11}$ For each measurement, three consecutive readings were taken just after blinking twice to minimise the effect of tear films. Image quality labelled with ' $\mathrm{OK}$ ' under the inspection window was accepted. All images covered the central $10.0 \mathrm{~mm}$ of corneal surface, without extrapolation in the central $9.0 \mathrm{~mm}$ zone. All measurements were taken between 10:00 and 17:00 by a trained operator (XYZ).

Routine examinations like uncorrected distance visual acuity (UDVA), CDVA and SE were also performed.

\section{Data collection}

For each eye, the best-fit sphere (BFS) in the central $8.0 \mathrm{~mm}$ zone of the preoperative cornea was used as the reference surface. The change in elevation is equal to postoperative elevation minus preoperative elevation, where a positive difference indicates forward displacement of the posterior surface.

Elevations were measured at the thinnest (posterior elevation at the thinnest point (PTE)) and maximal (posteriormaximal elevation (PME)) points in relation to preoperative BFS, in addition to the central (posteriorcentral elevation (PCE)) and at 24 other predetermined points on three concentric circles $(1,2$ and
$3 \mathrm{~mm}$ from the centre, along the $0^{\circ}, 45^{\circ}, 90^{\circ}, 135^{\circ}, 180^{\circ}, 225^{\circ}$, $270^{\circ}$ and $315^{\circ}$ semimeridians). PME is the highest elevation in the central area within $6 \mathrm{~mm}$ (taken directly from mouse-over read-out values). Posterior average elevation was calculated from the centre and 24 predetermined points. The average values of each concentric circle are denoted by PCE0 (one point, centre), PCE2 (eight points, $1 \mathrm{~mm}$ out from the centre), PCE4 (eight points, $2 \mathrm{~mm}$ out) and PCE6 (eight points, $3 \mathrm{~mm}$ out). These points are split symmetrically into nasal (posterior corneal elevation in nasal hemisphere (NPCE)) and temporal (posterior corneal elevation in temporal hemisphere (TPCE)) hemispheres by the $90^{\circ}-270^{\circ}$ meridian, and superior (posterior corneal elevation in superior hemisphere (SPCE)) and inferior (posterior corneal elevation in inferior hemisphere (IPCE)) hemispheres by the $0^{\circ}-180^{\circ}$ meridian. $0^{\circ}$ of the right eye is defined along the horizontal semimeridian pointing towards the right, with clockwise positive angles. Vice versa for the left eye, with counterclockwise positive angles.

\section{Statistical analysis}

Statistical analysis was performed using SAS system software V.9.4. The one-sample Kolmogorov-Smirnov test was used to test for normality. Continuous variables with normal distributions were denoted as average \pm SD. Mixed linear models for repeated measurements were employed to analyse the change in elevations over time and to compare the changes between different surgeries. Average change in elevations in different hemispheres and meridians were compared using paired $T$ tests. Pearson correlation analysis was used to evaluate the linear relationships between elevation changes and several variables, including preoperative refraction, preoperative intraocular pressure (IOP), preoperative thinnest corneal thickness, ablation depth (AD) and RBT. P $<0.05$ was considered statistically significant.

\section{RESULTS}

\section{Refractive outcomes}

Refractive outcomes are summarised in figure 1 . The safety index and effectiveness index at the 2-year follow-up was 1.29 and 0.96 , respectively. UDVA was $\geq 20 / 32$, $\geq 20 / 25$ and $\geq 20 / 20$ in 34 (100\%), 29 (85.29\%) and 21 (61.76\%) eyes, respectively. The SE of $14(41.18 \%)$ and $26(76.47 \%)$ eyes were within the range of \pm 0.50 and $\pm 1.00 \mathrm{D}$, respectively. Thirty-three $(97.06 \%)$ eyes remained stable or gained Snellen lines. Twenty-eight $(82.35 \%)$ gained one to three lines, while only one (2.94\%) lost one line. None lost two or more.

\section{Posterior corneal elevation}

See table 2 for postoperative elevation differences. With the exception of $\triangle$ TPCE $(p=0.026)$ in SMILE group and $\triangle$ PTE $(p=0.042)$ in FS-LASIK group, no significant changes over time were observed. $\triangle \mathrm{PME}$ at 1 day, $\triangle \mathrm{PCE}, \triangle \mathrm{PME}, \triangle \mathrm{NPCE}$, $\triangle$ SPCE, $\triangle \mathrm{PCE} 0, \triangle \mathrm{PCE} 2$ at 3 months and $\triangle \mathrm{SPCE}$ at 6 months after SMILE displayed non-significant forward displacements $(p>0.05)$. SPCE reverted to original levels within 2 years, while the rest reverted within 6 months. In FS-LASIK group, all elevations displayed non-significant forward displacements at 1 day postoperatively except $\triangle \mathrm{PTE}$ and $\triangle \mathrm{SPCE}$, and most reverted to original levels at long-term follow-up except $\triangle$ PCE6 and $\triangle$ IPCE. $\triangle \mathrm{TPCE}$ at 6 months $(\mathrm{p}=0.002), \triangle \mathrm{PTE}$ at 2 years $(p=0.015)$ after SMILE and $\triangle$ PTE at long-term follow-up $(p=0.019)$ after FS-LASIK displayed significant backward displacements. See figure 2 for the variation of elevations 


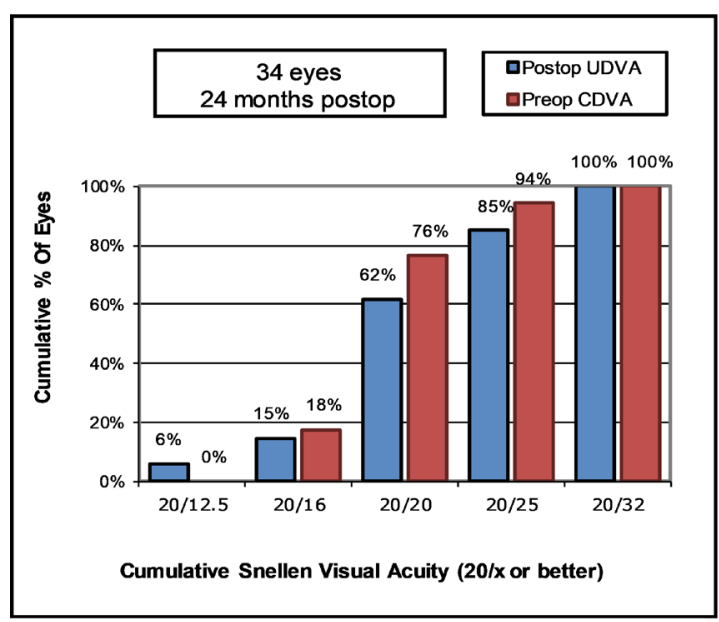

Uncorrected Distance Visual Acuity

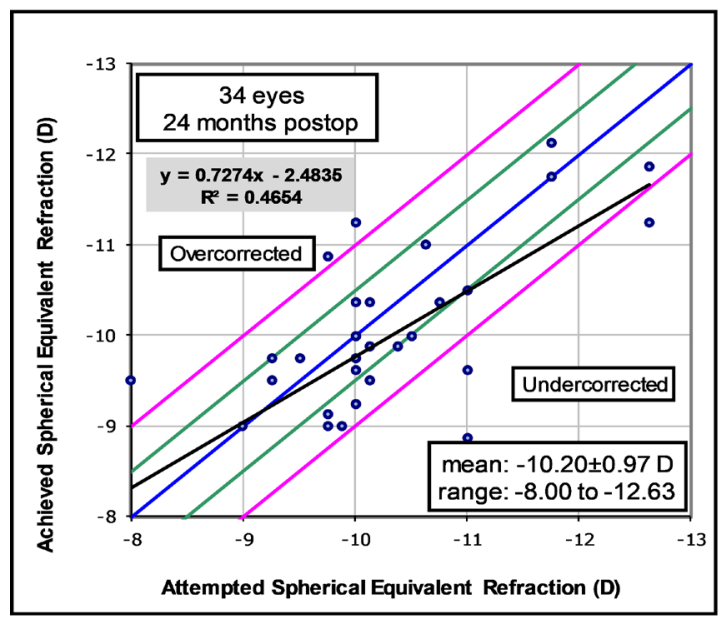

Spherical Equivalent Attempted vs Achieved

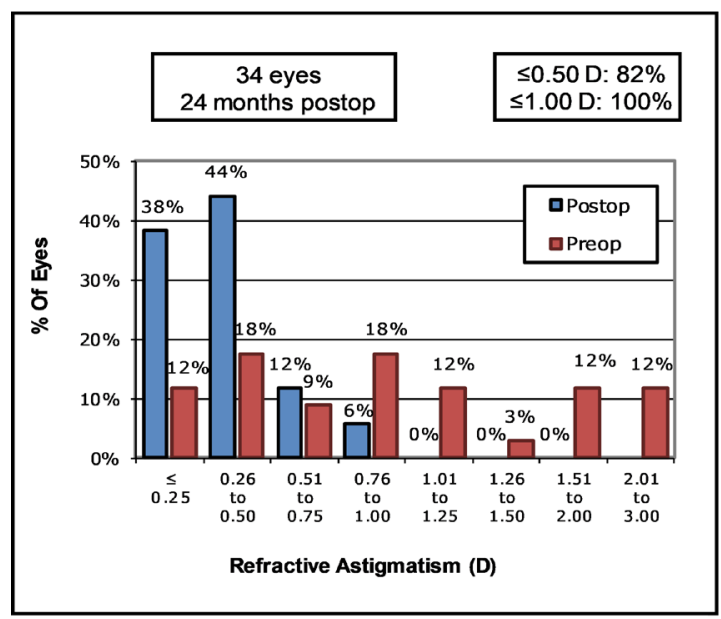

Refractive Astigmatism

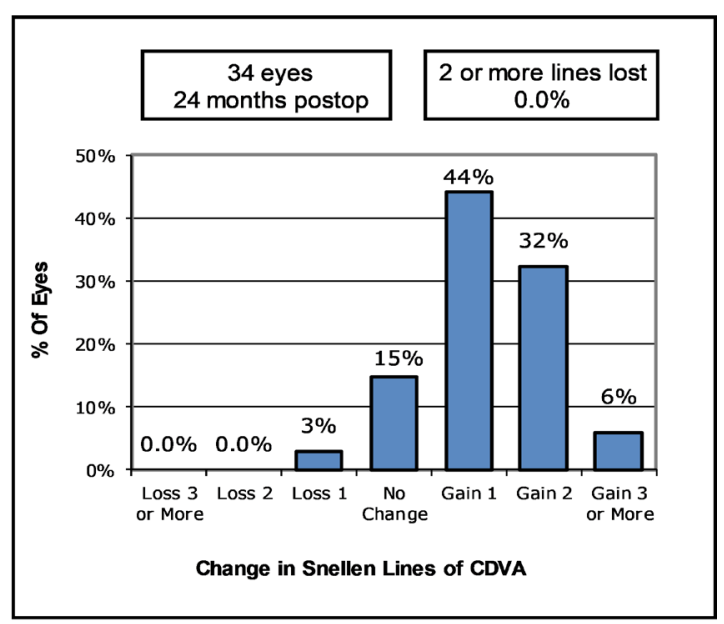

Change in Corrected Distance Visual Acuity

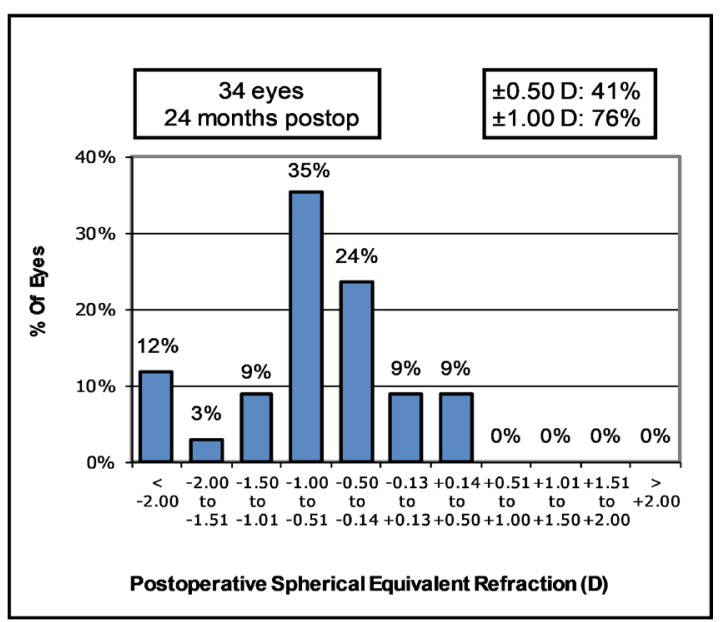

Spherical Equivalent Refractive Accuracy

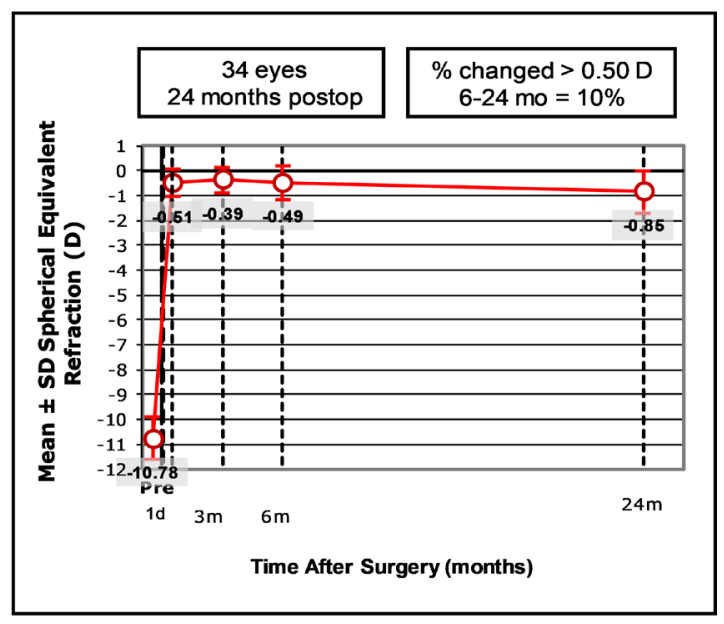

Stability of Spherical Equivalent Refraction

Figure 1 Refractive outcomes during the follow-up period after small-incision lenticule extraction (SMILE). CDVA,corrected distance visual acuity; $D$, dioptres; UDVA, uncorrected distance visual acuity.

in SMILE group on different points (A), hemispheres (B) and radii $(\mathrm{C})$. Most parameters reached peak anterior protrusion 3 months after surgery. Peak anterior protrusion occurred later at larger radii. No significant differences were detected between surgeries except TPCE $(p=0.003)$, PCE4 $(p=0.045)$ and PCE6 $(\mathrm{p}=0.013)$ (figure $2 \mathrm{D}, \mathrm{E}, \mathrm{F})$. TPCE at long-term follow-up was higher in FS-LASIK than SMILE $(\mathrm{p}=0.015)$. Meanwhile, PCE4 $(p=0.032)$ and PCE6 $(p=0.019)$ at 1 day, and PCE6 $(p=0.036)$ at long-term postoperatively were higher in FS-LASIK than SMILE. 
Table 2 Changes in posterior corneal elevations after SMILE and FS-LASIK

\begin{tabular}{|c|c|c|c|c|c|c|c|c|}
\hline \multirow{2}{*}{$\begin{array}{l}\text { Measuring } \\
\text { position }\end{array}$} & \multicolumn{4}{|c|}{ Postoperative period (SMILE) } & \multirow[b]{2}{*}{$P$ valuet } & \multicolumn{2}{|c|}{ Postoperative period (FS-LASIK) } & \multirow[b]{2}{*}{$P$ value $\dagger$} \\
\hline & 1 Day & 3 Months & 6 Months & 2 Years & & 1 Day & Long-term & \\
\hline PCE & $-0.69 \pm 2.63$ & $0.82 \pm 2.75$ & $-0.23 \pm 2.43$ & $-1.18 \pm 3.06$ & 0.410 & $0.25 \pm 1.62$ & $-0.59 \pm 1.40$ & 0.384 \\
\hline PTE & $-0.79 \pm 3.44$ & $-0.36 \pm 3.20$ & $-1.53 \pm 3.56$ & $-1.94 \pm 3.21^{*}$ & 0.138 & $-0.04 \pm 3.26$ & $-1.91 \pm 2.98^{*}$ & $0.042^{*}$ \\
\hline PME & $0.10 \pm 3.06$ & $0.32 \pm 3.00$ & $-0.58 \pm 2.76$ & $-0.47 \pm 3.07$ & 0.988 & $0.21 \pm 3.11$ & $-0.35 \pm 2.10$ & 0.421 \\
\hline PAE & $-0.57 \pm 2.20$ & $-0.00 \pm 2.39$ & $-0.06 \pm 2.38$ & $-0.63 \pm 2.91$ & 0.762 & $0.41 \pm 1.25$ & $-0.22 \pm 0.89$ & 0.237 \\
\hline \multicolumn{9}{|c|}{ Concentric circle } \\
\hline $2 \mathrm{~mm}$ & $-0.42 \pm 2.61$ & $0.35 \pm 2.75$ & $-0.10 \pm 2.72$ & $-0.99 \pm 2.89$ & 0.662 & $0.15 \pm 1.58$ & $-0.56 \pm 1.18$ & 0.449 \\
\hline $4 \mathrm{~mm}$ & $-0.87 \pm 2.28$ & $-0.21 \pm 2.55$ & $-0.18 \pm 2.38$ & $-0.92 \pm 2.50$ & 0.480 & $0.38 \pm 1.15$ & $-0.22 \pm 0.99$ & 0.281 \\
\hline $6 \mathrm{~mm}$ & $-0.63 \pm 1.81$ & $-0.62 \pm 2.57$ & $-0.01 \pm 2.12$ & $-0.67 \pm 2.06$ & 0.487 & $0.29 \pm 0.82$ & $0.13 \pm 0.98$ & 0.237 \\
\hline \multicolumn{9}{|l|}{ Hemisphere } \\
\hline NPCE & $-0.74 \pm 2.07$ & $0.52 \pm 2.55$ & $-0.03 \pm 2.72$ & $-0.55 \pm 2.88$ & 0.576 & $0.03 \pm 1.08$ & $-0.02 \pm 1.08$ & 0.917 \\
\hline TPCE & $-0.58 \pm 3.14$ & $-0.35 \pm 3.07$ & $-2.03 \pm 1.39^{*}$ & $-1.32 \pm 3.27$ & $0.026^{*}$ & $0.25 \pm 1.36$ & $-0.44 \pm 1.12$ & 0.362 \\
\hline IPCE & $-1.15 \pm 2.72$ & $-1.12 \pm 2.84$ & $-0.93 \pm 2.01$ & $-1.00 \pm 2.19$ & 0.386 & $1.57 \pm 2.18$ & $0.01 \pm 1.95$ & 0.179 \\
\hline SPCE & $-0.40 \pm 2.43$ & $0.77 \pm 2.80$ & $0.44 \pm 2.98$ & $-0.58 \pm 3.37$ & 0.545 & $-0.66 \pm 1.26$ & $-0.36 \pm 1.11$ & 0.833 \\
\hline
\end{tabular}

All data are expressed as the mean \pm SD $(\mu \mathrm{m})$.

${ }^{*} \mathrm{P}<0.05$.

tCompared to preoperation using mixed linear models for repeated measurements.

$\mathrm{PAE}$, posterior average elevation.

Figure 3 shows the variation of elevations at different radii and different angles. The trends in elevation change remain roughly consistent position-wise across time. Elevation fluctuations increased from the centre (difference at $2 \mathrm{~mm}$ diameter: SMILE, $1.41 \mu \mathrm{m}$; FS-LASIK, $2.82 \mu \mathrm{m}$ ) to the periphery (difference at 6 mm diameter: SMILE, $12.26 \mu \mathrm{m}$; FS-LASIK, $14.18 \mu \mathrm{m})$. In both procedures, elevations rose above the BFS along the $0^{\circ}-180^{\circ}$ meridian and dropped below the BFS along the $90^{\circ}-270^{\circ}$ meridian except at $2 \mathrm{~mm}$ diameter (SMILE: $2 \mathrm{~mm}$, horizontal, $2.01 \pm 2.73 \mu \mathrm{m}$, vertical, $0.72 \pm 2.63 \mu \mathrm{m}, \mathrm{p}<0.001 ; 4 \mathrm{~mm}$, horizontal, 3.99 $\pm 2.56 \mu \mathrm{m}$, vertical, $-1.12 \pm 2.41 \mu \mathrm{m}, \mathrm{p}<0.001$;
$6 \mathrm{~mm}$, horizontal, 5.96 $\pm 3.05 \mu \mathrm{m}$, vertical, $-1.12 \pm 2.41 \mu \mathrm{m}$, $\mathrm{p}<0.001$. FS-LASIK: $2 \mathrm{~mm}$, horizontal, $1.98 \pm 2.08 \mu \mathrm{m}$, vertical, $0.61 \pm 2.03 \mu \mathrm{m}, \mathrm{p}<0.001 ; 4 \mathrm{~mm}$, horizontal, $4.05 \pm 1.84$ $\mu \mathrm{m}$, vertical, $-0.93 \pm 1.78 \mu \mathrm{m}, \mathrm{p}<0.001 ; 6 \mathrm{~mm}$, horizontal, $6.30 \pm 2.43 \mu \mathrm{m}$, vertical, $-4.55 \pm 2.30 \mu \mathrm{m}, \mathrm{p}<0.001)$, forming two distinct peaks and valleys at all diameters. Furthermore, average elevations were significantly higher on the inferior hemisphere than on the superior hemisphere at all diameters (SMILE: $2 \mathrm{~mm}$, inferior, $1.28 \pm 3.19 \mu \mathrm{m}$, superior, $0.12 \pm 2.72$ $\mu \mathrm{m}, \mathrm{p}=0.005 ; 4 \mathrm{~mm}$, inferior, $-0.15 \pm 3.35 \mu \mathrm{m}$, superior, $-2.03 \pm 3.21 \mu \mathrm{m}, \mathrm{p}=0.011 ; 6 \mathrm{~mm}$, inferior, $-3.08 \pm 3.70 \mu \mathrm{m}$,
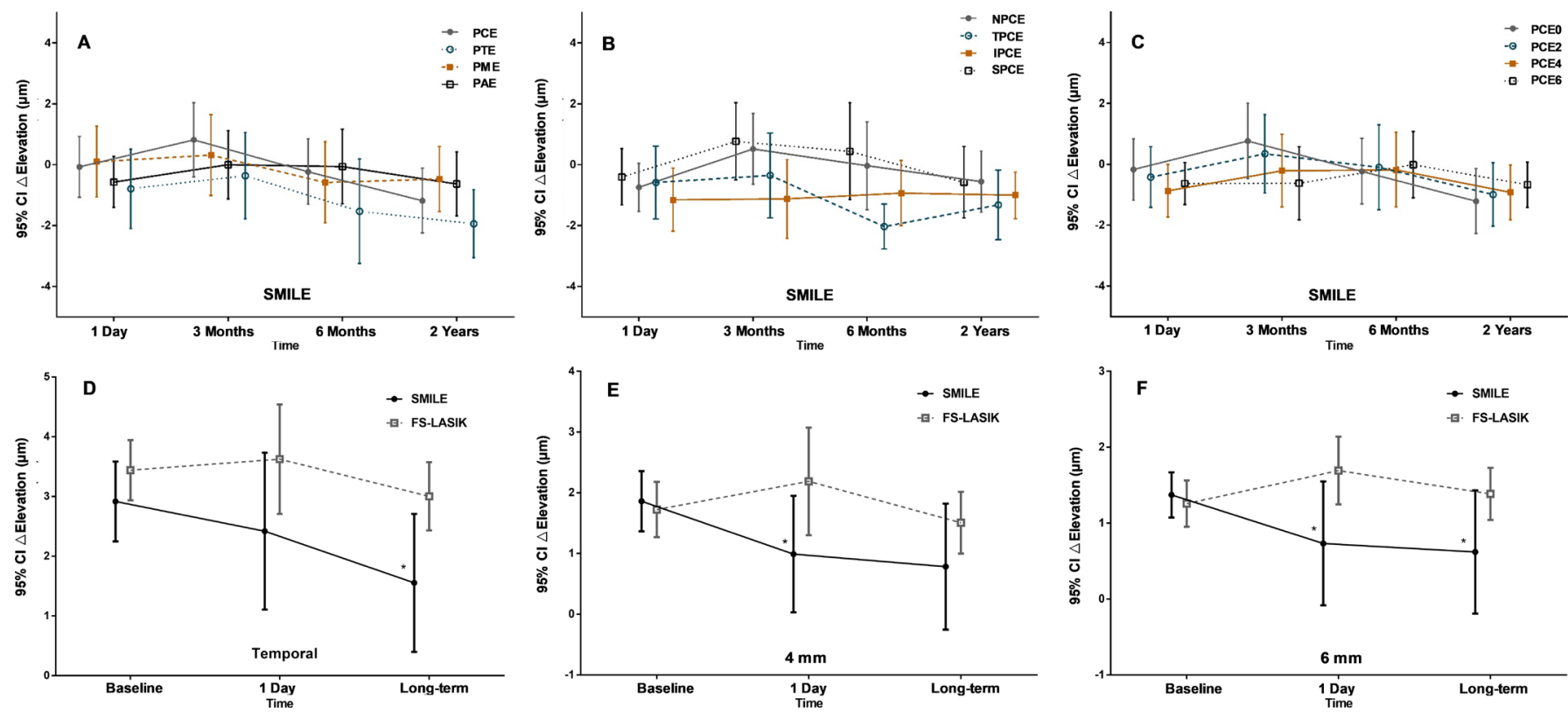

Figure 2 Change in posterior corneal elevations after small-incision lenticule extraction (SMILE) and comparison with femtosecond laser-assisted in situ keratomileusis (FS-LASIK). (A) Posterior central (PCE), maximal (PME), posterior average elevation (PAE) and at the thinnest point (PTE). (B) Changes in nasal (NPCE), temporal (TPCE), inferior (IPCE) and superior (SPCE) hemispheres. (C) Changes at centre (PCE0), 2 mm (PCE2), 4 mm (PCE4) and $6 \mathrm{~mm}$ (PCE6) diameters. With the exception of $\triangle T P C E(p=0.026)$, no significant changes over time were observed after SMILE. Significant differences between surgeries in TPCE (D), PCE4 (E) and PCE6 (F). Individual points and error bars represent the estimated mean and SD. *P<0.05 between SMILE and FS-LASIK. 

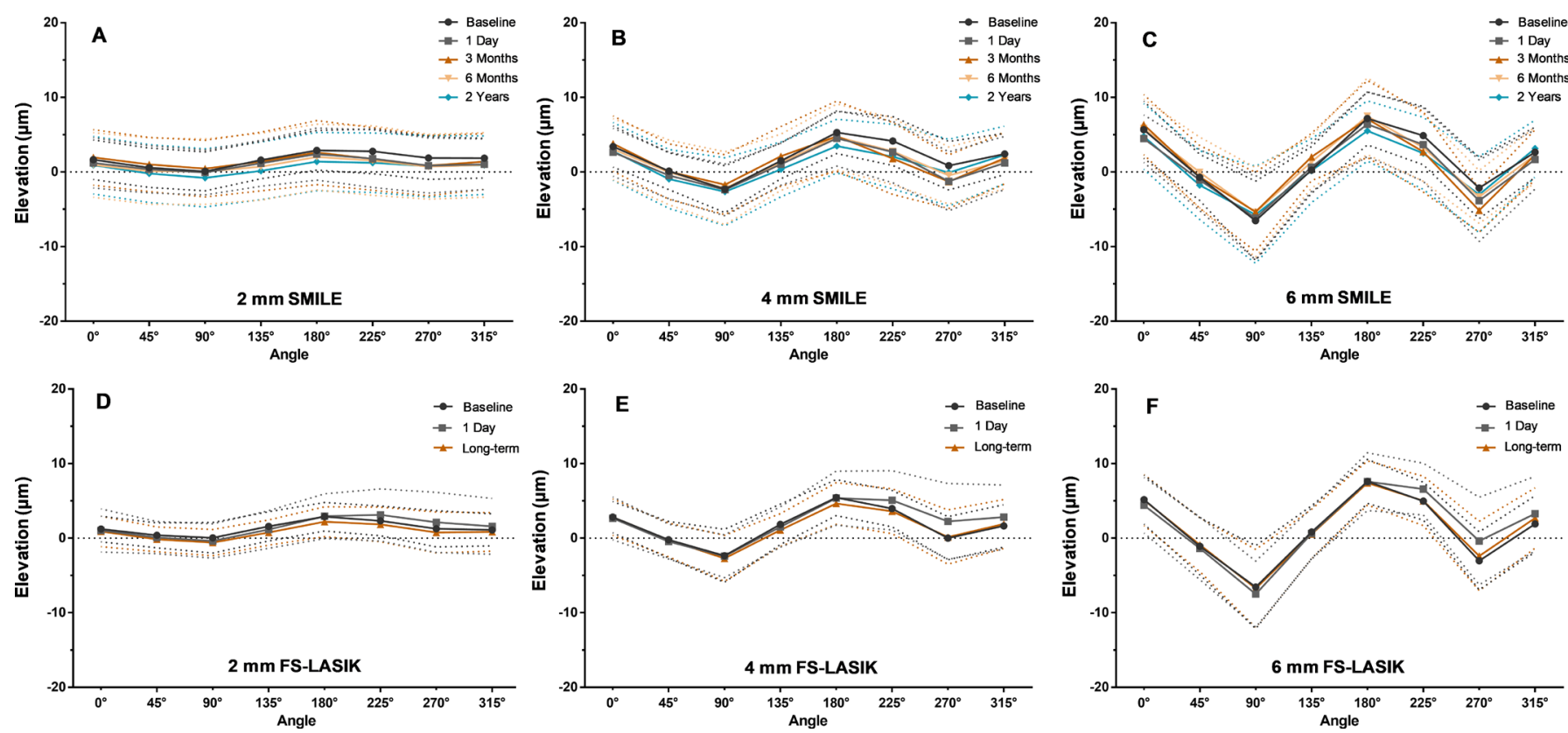

Figure 3 Posterior corneal elevations changes at various diameters from the perspective of the meridian after small-incision lenticule extraction (SMILE) and comparison with femtosecond laser-assisted in situ keratomileusis (FS-LASIK). (A-C) Variations at 2, 4 and 6 mm diameter in SMILE group. (D-F) Variations at 2, 4 and $6 \mathrm{~mm}$ diameter in FS-LASIK group. Individual points and dotted lines represent the estimated mean and SD.

superior, $-5.72 \pm 3.45 \mu \mathrm{m}, \mathrm{p}=0.008$. FS-LASIK: $2 \mathrm{~mm}$, inferior, $1.68 \pm 2.45 \mu \mathrm{m}$, superior, $0.50 \pm 2.22 \mu \mathrm{m}, \mathrm{p}=0.008$; $4 \mathrm{~mm}$, inferior, $2.21 \pm 2.79 \mu \mathrm{m}$, superior, $-0.30 \pm 2.58 \mu \mathrm{m}, \mathrm{p}=0.003$; $6 \mathrm{~mm}$, inferior, $1.80 \pm 3.15 \mu \mathrm{m}$, superior, $-2.32 \pm 3.38 \mu \mathrm{m}$, $\mathrm{p}<0.001)$. Elevations were also significantly higher on the temporal hemisphere than on the nasal hemisphere at all diameters apart from $6 \mathrm{~mm}$ in SMILE group (SMILE: $2 \mathrm{~mm}$, temporal, $2.40 \pm 2.95 \mu \mathrm{m}$, nasal, $1.59 \pm 2.89 \mu \mathrm{m}, \mathrm{p}=0.011 ; 4$ $\mathrm{mm}$, temporal, $4.52 \pm 2.97 \mu \mathrm{m}$, nasal, $3.29 \pm 2.87 \mu \mathrm{m}, \mathrm{p}=0.016$; $6 \mathrm{~mm}$, temporal, $6.39 \pm 3.69 \mu \mathrm{m}$, nasal, $5.38 \pm 3.45 \mu \mathrm{m}$, $\mathrm{p}=0.086$. FS-LASIK: $2 \mathrm{~mm}$, temporal, $2.13 \pm 1.92 \mu \mathrm{m}$, nasal, $0.96 \pm 2.34 \mu \mathrm{m}, \mathrm{p}<0.001 ; 4 \mathrm{~mm}$, temporal, $3.50 \pm 1.70 \mu \mathrm{m}$, nasal, $1.73 \pm 2.32 \mu \mathrm{m}, \mathrm{p}<0.001 ; 6 \mathrm{~mm}$, temporal, $4.38 \pm 1.63$ $\mu \mathrm{m}$, nasal, $2.34 \pm 2.32 \mu \mathrm{m}, \mathrm{p}<0.001)$.

\section{Correlation analysis}

In SMILE group, $\triangle$ PCE6 negatively correlates with RBT $(\mathrm{r}=-0.450, \mathrm{p}=0.047)$ at 3 months. Both $\triangle \mathrm{TPCE}$ and $\triangle \mathrm{PME}$ positively correlate with $\mathrm{AD}$ at 6 months $(\mathrm{r}=0.534, \mathrm{p}=0.033$ and $\mathrm{r}=0.489, \mathrm{p}=0.043$, respectively). $\triangle \mathrm{TPCE}, \triangle \mathrm{PCE} 4$ and $\triangle$ PCE6 correlate positively with preoperative IOP at 2 years $(\mathrm{r}=0.349, \mathrm{p}=0.043 ; \mathrm{r}=0.352, \mathrm{p}=0.048$ and $\mathrm{r}=0.380, \mathrm{p}=0.032$, respectively).

\section{DISCUSSION}

Orbscan II and Pentacam HR are the most commonly used instruments for measuring posterior corneal elevation. However, the accuracy of Orbscan II has been disputed, ${ }^{12}{ }^{13}$ being susceptible to overestimation of corneal elevations. ${ }^{14}$ Pentacam is accurate at measuring posterior elevations, which can be further improved by repeated measurements. ${ }^{15}$ Studies have confirmed that Pentacam can effectively distinguish the posterior elevations of keratoconus, subclinical keratoconus and normal corneas with high sensitivity and specificity, ${ }^{6}$ which serves as one of the most effective parameters for corneal ectasia diagnosis. ${ }^{16}$

The average PCE and PTE at 2 years postoperatively were 0.15 and $1.38 \mu \mathrm{m}$, respectively, close to the results (median of
0.0 and $3 \mu \mathrm{m}$ ) reported by Ying et al, who conducted a large cross-sectional study of 1500 Chinese corneal refractive surgery patients. ${ }^{17}$ Furthermore, all elevation changes were within Pentacam's $\pm 5 \mu \mathrm{m}$ measurement error range (95\% limits of agreement: 4.27 to $-5.29 \mu \mathrm{m}$ at the $5 \mathrm{~mm}$ zone). ${ }^{15}$ This indicates that the posterior corneal surface remains stable 2 years after SMILE for extremely high myopia.

Only a few studies researched corneal elevations after SMILE, and all reported elevation changes within measurement error range of $\pm 5 \mu \mathrm{m} .{ }^{1118-20}$ No significant forward displacements were observed postoperatively except during early stages of recovery. ${ }^{18}$ Zhao et $a l^{11}$ and Wang et $a l^{19}$ reported stable posterior corneal surfaces in eyes with moderate to high myopia the first year following SMILE, which is supplemented by our research group's 3 years study (mean change at 3 years: PCE, $-2.39 \pm 2.85 \mu \mathrm{m}, \mathrm{p}<0.05$; PME, $0.50 \pm 3.33$ $\mu \mathrm{m}, \mathrm{p}=1.000 ;$ PTE, $-2.33 \pm 2.90 \mu \mathrm{m}, \mathrm{p}<0.05) .{ }^{20}$ This study provides long-term evidence for myopia higher than $-10 \mathrm{D}$ with slightly different results (mean change at 2 years: PCE, $-1.18 \pm 3.06 \mu \mathrm{m}, \mathrm{p}>0.05 ;$ PME, $-0.47 \pm 3.07 \mu \mathrm{m}, \mathrm{p}>0.05$; PTE, $-1.94 \pm 3.21 \mu \mathrm{m}, \mathrm{p}<0.05)$. Grewal et al ${ }^{21}$ found forward displacements of $5.13 \pm 4.16,5.78 \pm 4.42$ and $6.68 \pm 4.72 \mu \mathrm{m}$ 18 months after LASIK with three different methods of flap creation, respectively. These displacements seem all higher than that of SMILE and beyond Pentacam's measurement error range. Moreover, posterior elevation following FS-LASIK is significantly higher than that of SMILE one year postoperatively for high myopia. ${ }^{19}$ Our results agree with the previous study and provide complementary evidence for extremely high myopia. It is reasonable to presume that posterior surface was more stable after SMILE compared with LASIK.

Interestingly, there were slight but significant backward changes of NPCE in SMILE and PTE in FS-LASIK group. These backward shifts were previously observed after various refractive surgeries including photorefractive keratectomy (PRK) ${ }^{22}$ LASIK $^{23}$ and SMILE, ${ }^{20}$ but the reason is still unclear. One possible explanation may be the hyperopic shift caused 
by flattening of the central cornea and thickening of peripheral stroma postoperatively, as demonstrated following PTK. ${ }^{20}$ Considering those backward shifts are still within measurement error, we need further investigation to explore the practical implications.

Some postoperative corneal biomechanical properties may partly explain the advantage of the posterior surface stability after SMILE. Corneal strength decreases non-linearly with increasing depth, with the anterior $40 \%$ of the surface bearing most of its strength, culminating on the Bowman's membrane. ${ }^{24} 25$ Several mathematical models and clinical studies confirmed that SMILE is better at preserving the corneal surface and biomechanical stability compared with LASIK, and the difference is even more pronounced for thinner corneas in high-myopia cases. ${ }^{426-28}$

In this study, the vast majority of elevations returned to original levels 6 months after SMILE. We found a slight overall backward displacement the first day postoperatively, followed by continued backward trend in the peripheral area, and a reversed forward trend in the central area after 3-6 months. This is in alignment with previous study, which revealed similar variability in elevations after LASIK, with the $2 \mathrm{~mm}$ diameter circle being the boundary between forward and backward displacements. ${ }^{29}$ Ganesh et al found an increase of negative keratometric power and prolate asphericity following ReFlex SMILE, especially in the central area, with higher impact as diopters increased. ${ }^{30}$ Conversely, Yu and associates ${ }^{18}$ found a backward trend in the central area and a forward trend in the peripheral area after SMILE. This may be due to the lower severity of myopia in their study (preop SE: $-5.58 \pm 1.29$ D). Higher myopia calls for thicker extractive lenticule and deeper ablation, leaving more interspace behind. Together with the remaining tensile strength of the uncut peripheral corneal cap, this may cause the posterior central elevation to compensate more than the peripheral elevation via a higher forward displacement.

The elevation was significantly higher on the horizontal meridian, inferior and temporal hemisphere than the vertical meridian, superior and nasal hemisphere, except for PCE6 in SMILE. The elevation differences between the orthogonal meridians and corresponding hemispheres grew larger as distances from the centre increased. The above results agree with previous reports. ${ }^{29}$ The difference between horizontal and vertical meridians maybe closely associated with the high incidence of withthe-rule astigmatism among young people. ${ }^{31}$

$\triangle \mathrm{PCE}$ was found to negatively correlate with RBT, and positively with $\mathrm{AD}$ and preoperative $\mathrm{IOP}$, corresponding to previous study. ${ }^{8}$ Curiously, our research group reported opposite results in a previous study: $\triangle \mathrm{PCE}$ positively correlated with RBT and negatively with $\mathrm{AD}$ at 12 months postoperatively. ${ }^{11}$ In this study, the negative correlation between RBT and $\triangle \mathrm{PCE}$ was found in the peripheral cornea, while the previous study focused on the central $4 \mathrm{~mm}$ area. The opposite displacements of the central (forward) and peripheral (backward) cornea in our study are likely the explanation. Notably, Reinstein et $a l^{28}$ found that deeper lenticule tissue removal and lower RBT leads to a $0.08 \% / \mu \mathrm{m}$ increase in corneal tensile strength, challenging earlier understandings of SMILE. Moreover, other studies have found that SMILE with deeper ADs have counterintuitively less impact on corneal biomechanics. ${ }^{32}$ Thus, more evidence is needed to disentangle the effects of $\mathrm{AD}$ and $\mathrm{RBT}$ on corneal biomechanics.

One limitation of our study is that we currently lack standard guidelines for measuring posterior corneal elevation. Given the complexity and asphericity of the cornea, a toric or aspheric reference surface may better reflect its real shape and biomechanical behaviour, compared with a spherical shape. The largesample cross-sectional analysis found a correlation between BFS-based posterior corneal elevations and astigmatism, ${ }^{17}$ in this regard, best fit toric ellipsoid (BFTE) is less affected by astigmatism and superior to BFS at differentiating between normal cornea, keratoconus and forme fruste keratoconus. ${ }^{33} 34$ We chose BFS based on the habit of clinical practice, but possibly BFTE could be a better choice for patients with high astigmatism in this study (up to $-4.50 \mathrm{D}$ ).

In conclusion, this study confirms the long-term stability of posterior corneal elevation in eyes with myopia higher than -10.00 D following SMILE and shows advantage of stability over FS-LASIK. Narrowing the scope of this study to extreme myopia is a limitation which can be mitigated with additional investigation of patients with more diverse degrees of myopia and astigmatism.

Contributors $X Y Z$, JS and $X T Z$ : design of the study. $X Y Z$, JS and BQ: conduct of the study. XYZ, JS, BQ and YZ: data collection. XYZ, JS and XTZ: analysis and interpretation of data. XYZ, YZ and XTZ: edits and revisions. XTZ: final approval of article.

Funding This study was supported by the National Natural Science Foundation of China (Grant No. 81770955, No.81570879) and the Project of Shanghai Science and Technology (Grant No. 17140902900, No. 17411950200).

Competing interests None declared.

\section{Patient consent for publication Not Required}

Ethics approval This study was approved by the Ethical Committee of the Fudan University EENT Hospital Review Board.

Provenance and peer review Not commissioned; externally peer reviewed.

Data availability statement All data relevant to the study are included in the article or uploaded as supplementary information.

Open access This is an open access article distributed in accordance with the Creative Commons Attribution Non Commercial (CC BY-NC 4.0) license, which permits others to distribute, remix, adapt, build upon this work non-commercially, and license their derivative works on different terms, provided the original work is properly cited, appropriate credit is given, any changes made indicated, and the use is non-commercial. See: http://creativecommons.org/licenses/by-nc/4.0/.

\section{ORCID iD}

Xingtao Zhou http://orcid.org/0000-0002-6125-769X

\section{REFERENCES}

1 Shah R, Shah S, Sengupta S. Results of small incision lenticule extraction: all-in-one femtosecond laser refractive surgery. I Cataract Refract Surg 2011;37:127-37.

2 Sekundo W, Kunert KS, Blum M. Small incision corneal refractive surgery using the small incision lenticule extraction (SMILE) procedure for the correction of myopia and myopic astigmatism: results of a 6 month prospective study. Br J Ophthalmol 2011;95:335-9.

3 Pedersen IB, Ivarsen A, Hjortdal J. Three-year results of small incision Lenticule extraction for high myopia: refractive outcomes and aberrations. J Refract Surg 2015;31:719-24

4 Wu D, Wang Y, Zhang L, et al. Corneal biomechanical effects: small-incision lenticule extraction versus femtosecond laser-assisted laser in situ keratomileusis. J Cataract Refract Surg 2014:40:954-62.

5 Belin MW, Khachikian SS. An introduction to understanding elevation-based topography: how elevation data are displayed - a review. Clin Exp Ophthalmol 2009;37:14-29.

6 de Sanctis U, Loiacono C, Richiardi L, et al. Sensitivity and specificity of posterior corneal elevation measured by Pentacam in discriminating keratoconus/subclinical keratoconus. Ophthalmology 2008:115:1534-9.

7 Miháltz K, Kovács I, Takács A, et al. Evaluation of keratometric, pachymetric, and elevation parameters of keratoconic corneas with Pentacam. Cornea 2009;28:976-80

8 Baesk T, Lee K, Kagaya F, et al. Factors affecting the forward shift of posterior corneal surface after laser in situ keratomileusis. Ophthalmology 2001;108:317-20.

9 Smadja D, Santhiago MR, Mello GR, et al. Response of the posterior corneal surface to myopic laser in situ keratomileusis with different ablation depths. J Cataract Refract Surg 2012;38:1222-31 
10 Yao P, Zhao J, Li M, et al. Microdistortions in Bowman's layer following femtosecond laser small incision lenticule extraction observed by Fourier-Domain OCT. J Refract Surg 2013;29:668-74.

11 Zhao Y, Li M, Zhao J, et al. Posterior corneal Elevation after small incision Lenticule extraction for moderate and high myopia. Plos One 2016;11:e0148370.

12 Cairns G, McGhee CNJ. Orbscan computerized topography: attributes, applications, and limitations. J Cataract Refract Surg 2005;31:205-20.

13 Cairns G, Ormonde SE, Gray T, et al. Assessing the accuracy of Orbscan II post-LASIK: apparent keratectasia is paradoxically associated with anterior chamber depth reduction in successful procedures. Clin Exp Ophthalmol 2005;33:147-52.

14 Quisling S, Sjoberg S, Zimmerman B, et al. Comparison of Pentacam and Orbscan IIz on posterior curvature topography measurements in keratoconus eyes. Ophthalmology 2006;113:1629-32.

15 Chen D, Lam AKC. Intrasession and intersession repeatability of the Pentacam system on posterior corneal assessment in the normal human eye. J Cataract Refract Surg 2007;33:448-54.

16 Kamiya K, Ishii R, Shimizu K, et al. Evaluation of corneal elevation, pachymetry and keratometry in keratoconic eyes with respect to the stage of Amsler-Krumeich classification. Br J Ophthalmol 2014;98:459-63.

17 Ying J, Wang Q, Belin MW, et al. Corneal elevation in a large number of myopic Chinese patients. Cont Lens Anterior Eye 2016;39:185-90.

18 Yu C, Wang Y, Su X, et al. An analysis of changes in posterior corneal elevation and relevant factors after small incision lenticule extraction. Zhonghua Yan Ke Za Zhi 2016:52:494-8

19 Wang B, Zhang Z, Naidu RK, et al. Comparison of the change in posterior corneal elevation and corneal biomechanical parameters after small incision lenticule extraction and femtosecond laser-assisted LASIK for high myopia correction. Cont Lens Anterior Eye 2016;39:191-6.

20 Zhao Y, Jian W, Chen Y, et al. Three-year stability of posterior corneal Elevation after small incision Lenticule extraction (SMILE) for moderate and high myopia. J Refract Surg 2017;33:84-8.

21 Grewal DS, Brar GS, Grewal SPS. Posterior corneal Elevation after LASIK with three flap techniques as measured by Pentacam. J Refract Surg 2011;27:261-8.

22 Kim SW, Sun HJ, Chang JH, et al. Anterior segment measurements using Pentacam and Orbscan II 1 to 5 years after refractive surgery. J Refract Surg 2009:25:1091-7.
23 ME S, Ramirez-Miranda A, Zarei-Ghanavati S, et al. Comparison of posterior corneal imaging before and after LASIK using dual rotating scheimpflug and scanning slit-beam corneal tomography systems. J Refract Surg 2013;29:96-101. 27.

24 Dawson DG, Grossniklaus HE, McCarey BE, et al. Biomechanical and wound healing characteristics of corneas after excimer laser keratorefractive surgery: is there a difference between advanced surface ablation and sub-Bowman's keratomileusis? J Refract Surg 2008;24.

25 Randleman JB, Dawson DG, Grossniklaus HE, et al. Depth-dependent cohesive tensile strength in human donor corneas: implications for refractive surgery. JRS 2008;24:S85-S89.

26 Sinha Roy A, Dupps WJ, Roberts CJ. Comparison of biomechanical effects of smallincision lenticule extraction and laser in situ keratomileusis: finite-element analysis. J Cataract Refract Surg 2014;40:971-80.

27 Wang D, Liu M, Chen Y, et al. Differences in the corneal biomechanical changes after SMILE and LASIK. J Refract Surg 2014;30:702-7.

28 Reinstein DZ, Archer TJ, Randleman JB. Mathematical model to compare the relative tensile strength of the cornea after PRK, LASIK, and small incision lenticule extraction. J Refract Surg 2013:29:454-60.

29 Zhang L, Wang Y. The shape of posterior corneal surface in normal, post-LASIK, and Post-epi-LASIK eyes. Invest Ophthalmol Vis Sci 2010;51:3468-75.

30 Ganesh S, Patel U, Brar S. Posterior corneal curvature changes following refractive small incision Lenticule extraction. OPTH 2015;9:1359-64.

31 Pérez-Escudero A, Dorronsoro C, Sawides L, et al. Minor influence of myopic laser in situ keratomileusis on the posterior corneal surface. Invest. Ophthalmol. Vis. Sci. 2009:50:4146-54.

32 Mohamed-Noriega K, Riau AK, Lwin NC, et al. Early corneal nerve damage and recovery following small incision lenticule extraction (SMILE) and laser in situ keratomileusis (LASIK). Invest. Ophthalmol. Vis. Sci. 2014;55:1823-34.

33 Smadja D, Santhiago MR, Mello GR, et al. Influence of the reference surface Shape for discriminating between normal corneas, subclinical keratoconus, and keratoconus. J Refract Surg 2013;29:274-81.

34 Kovács I, Miháltz K, Ecsedy M, et al. The role of reference body selection in calculating posterior corneal elevation and prediction of keratoconus using rotating scheimpflug camera. Acta Ophthalmologica 2011;89:e251-6. 